\title{
Recognition of hypochondriasis in a clinic for sexually transmitted disease
}

\author{
DAVID P FROST \\ From the Academic Department of Psychiatry, Middlesex Hospital Medical School, London WI
}

SUMMARY A descriptive study of 100 consecutive patients referred for psychiatric assessment from a clinic for sexually transmitted disease (STD) is reported. Thirty six patients presented with physical symptoms for which no organic cause could be found. Various physical and psychological features of the overall presentation of this "somatic" group were identified. These are discussed in terms of diagnostic categories, aetiological mechanisms, and theories of illness behaviour. The importance of directly observable aspects of the patients' consultation behaviour is stressed over and above deep psychological constructs. The diagnosis of hypochondriasis is seen as essentially a medical one, which entails the doctor making a set of judgements that require a broad clinical perspective.

\section{Introduction}

A large proportion of patients attending clinics for sexually transmitted disease (STD) are not found to be suffering from any physical disease. Many of these have come for routine checks or reassurance, and their attendance at the clinic can be seen as both reasonable and appropriate. Such consultation behaviour is the result of normal psychological processes to do with concern for health, interpretation of physical signs, and recognition of subjective symptoms. If these psychological processes are disordered, the patient may attend the clinic without rational grounds for doing so.

The extent to which psychological factors influence attendance at the clinic is still the subject of controversy. Bhanyi and Mahony have argued the case for more liaison psychiatry in STD clinics on the grounds that the clientele contains a high proportion of potential psychiatric patients.' Pedder and Goldberg found a higher incidence of psychiatric morbidity in clinic attenders whose presenting complaints were not typical of venereal disease. ${ }^{2}$ On the other hand, Catalan et $a l^{3}$ and Mayou ${ }^{4}$ were unable to detect any greater psychiatric morbidity in clinic attenders with no physical disorder. Catalan et al suggested that doctors are more likely to recognise psychological disturbances if the results of physical investigation prove negative. ${ }^{3}$ It is also possible that

Address for reprints: Dr D P Frost, lecturer in Psychiatry, Academic Department of Psychiatry, Middlesex Hospital Medical School, London WI

Accepted for publication 7 May 1984 morbid concern about venereal disease may delay rather than facilitate attendance at the clinic. ${ }^{5}$

Although the prevalence of psychiatric disturbance in STD clinics is in the order of $20-40 \%$, those referred for psychiatric assessment represent only $0 \cdot 3-1 \cdot 0 \%$ of new clinic attenders. ${ }^{2-4}$ These patients therefore represent a highly selected subsample of the clinic population. A proportion of the patients referred have complaints that are predominantly or exclusively physical. The study reported here is a descriptive survey of this "somatic group".

\section{Patients and methods}

The study was conducted at the department of genitourinary medicine at this hospital, and covered referrals to the on site liaison psychiatric service during $\mathbf{3 0}$ months. Referrals were accepted from the doctors, social workers, and nursing staff. I saw each patient for a standard psychiatric assessment interview, and obtained demographic and medical information from the clinic case notes. The patients were initially classified on the basis of their psychiatric presentation. This was used to identify a subgroup whose predominant or exclusive complaints were somatic. I then studied in detail the demographic, medical, and psychological characteristics of the somatic subgroup. I reviewed the medical case notes after follow up for two to 32 months to assess the nature of subsequent clinic attendance.

A system of descriptive categories covering various aspects of hypochondriasis was constructed from several sources. ${ }^{16}$ An initial distinction was made between features of morbid bodily concern and of 
illness behaviour. Morbid bodily concern was used to describe a state of anxious preoccupation with the possibility of illness, usually resulting from the misperception or misinterpretation of physical signs or symptoms. Illness behaviour was used to refer to the emotional, behavioural, and interpersonal phenomena associated with morbid bodily concern.

The features of morbid bodily concern were broken down into three components: nosophobia, psychogenic pain, and misperceptions. Nosophobia, or disease phobia, was defined as a persistent unfounded fear of disease. These patients were convinced of the presence of disease despite negative evidence and reassurance. Psychogenic pain was identified by its atypical distribution, which extended over a volume of the body image rather than following the anatomical distribution of particular peripheral nerves. Psychogenic pain was distinguished from psychosomatic reactions, in which functional changes were found on examination. Misperception and misinterpretation of physical signs were readily identified as the "abnormal" signs reported by patients turned out to be within normal limits on subsequent physical examination.

Illness behaviour was also broken down into three component features: consultation behaviour, affective distress, and psychological defensiveness. Consultation behaviour was defined by a set of attitudes and associated behaviour patterns that characterised the relationship between doctor and patient. This included a failure to be reassured, demands for more investigations, frequent reattendance, hostility, and accusations directed towards the medical staff. Affective distress was a readily identified aspect of a patient's mental state. Psychological defensiveness was evaluated by the extent of the patient's reluctance to engage in the discussion of psychological issues.

\section{Results}

During the $\mathbf{3 0}$ months of this study 100 patients were referred for psychiatric assessment. Table I shows that this represented an incidence of $0.4 \%$ among new clinic attenders, although the incidence would have been much lower if re-attenders had been included. A greater proportion of men than women were referred.
TABLE I Psychiatric referrals during 30 months

\begin{tabular}{llc}
\hline Sex & $\begin{array}{l}\text { No of new } \\
\text { STD clinic } \\
\text { attenders }\end{array}$ & $\begin{array}{l}\text { No }(\%) \text { of } \\
\text { psychiatric } \\
\text { referrals }\end{array}$ \\
\hline Men & 13152 & $79(0 \cdot 6)$ \\
Women & 10412 & $21(0 \cdot 2)$ \\
Total & 23564 & $100(0 \cdot 4)$ \\
\hline
\end{tabular}

Table II shows the initial classification of referrals on the basis of their psychiatric presentation in the studies by Pedder, ${ }^{2}$ Bhanyi and Mahoney, ${ }^{1}$ and the study reported here. Three main groups were seen: patients with somatic complaints (36 in this report), sexual dysfunction (28), and psychiatric disorders (36). Table III shows that patients with somatic complaints differed from the other two groups of patients in their sex and sexual orientation. Heterosexual men tended to present with somatic rather than psychological symptoms. In contrast only three homosexual men were found in the somatic group, while homosexuals accounted for most of the psychiatric presentations. Women presented equally with psychological and somatic complaints.

TABLE II Psychiatric classification in three studies

\begin{tabular}{lccc}
\hline $\begin{array}{l}\text { Pedder } \\
\text { Presentation }\end{array}$ & $\begin{array}{l}\text { Bhanyi and } \\
\text { Mahoney }\end{array}$ & $\begin{array}{l}\text { This } \\
\text { (16 months) }\end{array}$ & $\begin{array}{l}\text { (6 months) } \\
\text { (30 months) }\end{array}$ \\
\hline Physical complaints & 3 & 4 & 36 \\
Sexual dysfunction & 5 & 2 & 28 \\
Depression & 6 & 5 & 15 \\
Character disorder & 21 & 5 & 18 \\
Others & 5 & & 3 \\
Total & 40 & 16 & 100 \\
\hline
\end{tabular}

The somatic group consisted of a very heterogeneous collection of patients. The following clinical vignettes illustrate the range of presentations:

\section{CASE 1}

A 35 year old Cypriot man had an eight year history of specific fear of syphilis and two episodes of gonococcal urethritis, but no current symptoms or signs of STD. He was homosexual and had been promiscuous in his mid twenties, but was now living

TABLE III Sexual orientation of psychiatric referrals

\begin{tabular}{llcc}
\hline & No $(\%)$ of men & No $(\%)$ of women \\
\cline { 2 - 4 } Presentation & Heterosexuals & Homosexuals & \begin{tabular}{l} 
heterosexuals \\
\hline Physical complaints $(\mathrm{n}=36)$
\end{tabular} \\
Sexual dysfunction $(\mathrm{n}=28)$ & $20(55 \cdot 5)$ & $3(0 \cdot 1)$ & $13(36 \cdot 1)$ \\
Other psychiatric disorders $(\mathrm{n}=36)$ & $18(64 \cdot 3)$ & $10(35 \cdot 7)$ & $0(0)$ \\
\hline
\end{tabular}


with his boyfriend and was very careful about his choice of sexual partner. Each time he attended the clinic he.presented in a severe anxiety state, with obsessional ruminations about syphilis, "filth in the blood", prostitutes, and the "repulsive amoral society". He had rituals concerning cleanliness.

CASE 2

A 43 year old businessman had an eight year history of pain in his penis, testes, and lower abdomen after ejaculation and of non-specific urethritis (NSU) on one occasion, but had no evidence of current infection. He was heterosexual, married, and had two children. He had regular extramarital relations, especially on business trips to the Far East. His current symptoms dated from an encounter in Bangkok that he described as a "sexual awakening". He had no sense of guilt, but rather a veiled contempt for women. He was hostile to psychiatric assessment.

CASE 3

A 26 year old woman copywriter had an eight month history of a painful swollen vulva, but no history of STD. Slight vulvovaginitis was noted on one visit, but was not supported by subsequent examination. She had had an unhappy childhood and adolescence, and suffered from asthma and acne. She had been married for three years to a rather cold distant man, was unhappy about the direction of her life, and had mild neurotic type depression.

\section{MORBID BODILY CONCERN}

Morbid bodily concern was readily identified in 26 $(72 \%)$ of the 36 patients in the somatic group. Thirteen of these patients had nosophobia, with clear obsessional preoccupations concerning the possibility of disease, and an absolute failure to be reassured by negative findings. Fear of no particular disease predominated; diseases feared included herpes, syphilis, NSU, and pelvic inflammatory disease. Most of these patients had pronounced obsessional personalities, and the ruminations about venereal disease had all the qualities of obsessional compulsive neurosis.

Atypical patterns or distributions of symptoms suggestive of a psychogenic origin were found in nine patients. Table IV shows that such symptoms were reported more frequently in patients with no previous history of STD.

Thirteen patients reported "abnormal" physical signs that were not confirmed on physical examination. These included urethral discharge, changes in the scrotal skin, swollen vulva, and perianal lesions. They were mostly due to misinterpretation, but in three cases the conviction of abnormal physical
TABLE IV History of STD and nature of current presentation

\begin{tabular}{lll}
\hline & \multicolumn{2}{c}{ Current physical presentation } \\
\cline { 2 - 3 } & Typical & Atypical \\
\hline $\begin{array}{l}\text { History of STD } \\
\text { No history of STD }\end{array}$ & 14 & 3 \\
P<0.05, $\chi^{2}$ test. & 5 & 6 \\
\hline
\end{tabular}

appearance was held with a delusional intensity that was suggestive of dysmorphophobia.

The three components of morbid bodily concern occurred in various combinations, (figure) and were relatively easily identified. There were, however, 10 patients within the somatic group for whom no clear cut evidence of morbid bodily concern could be found. Of these 10 patients, eight had a history of STD in which they had experienced a similar collections of symptoms. Their inclusion within the somatic group therefore depended solely on the identification of illness behaviour.

\section{ILLNESS BEHAVIOUR}

The most obvious features of consultation behaviour were dissatisfaction and hostility. Three patients were openly hostile in talking about their treatment by the physicians, but many more were clearly dissatisfied with the clinic.

Affective distress was evident in about half the patients. This was usually a mild to moderate depression of a neurotic type with varying degrees of manifest anxiety. There were no reliable indicators as to whether this depression was part of a primary psychiatric disturbance or whether it was an understandable reaction to unexplained physical symptoms.

In $29(80 \%)$ of the 36 somatic cases it was impossible to engage the patient over any psychological issue. These patients tended to be defensive and hostile to the exploration of their personal life. An

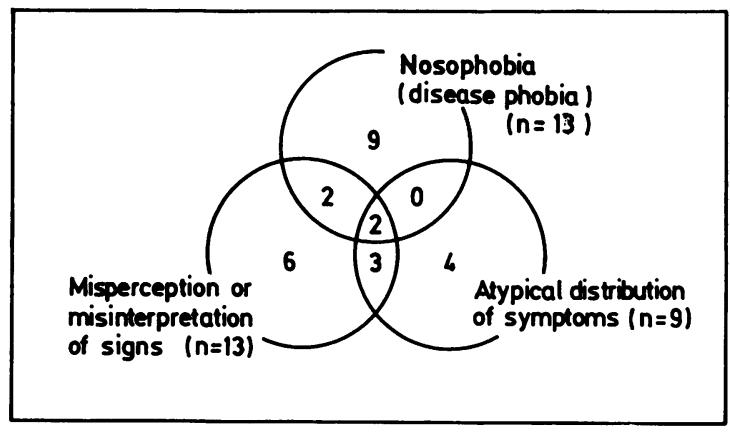

FIGURE Distribution of clearly identifiable cases of morbid bodily concern. 
indication of this defensiveness can be seen in the immediate outcome of the psychiatric consultation. Only seven patients (19\% of the somatic group) took up the offer of a further interview and returned for one or more sessions. Half the group did not return to the STD clinic at all during the follow up period. (Of the patients who did return, none developed any identifiable physical disorder to account for their original symptoms.) Of the patients that continued to attend the liaison psychiatry clinic, four were eventually referred for psychotherapy, and two for behaviour therapy.

\section{Discussion}

The presentation of psychological disturbance in the form of somatic symptoms or concern is increasingly being recognised as an important feature of the primary health care setting. The extent to which such somatic presentations are represented in the patient populations of STD clinics is unknown. Studies of patients referred to liaison psychiatric clinics have identified an appreciable group of patients with predominantly physical complaints (table II). ${ }^{17}$

The somatic presentation of psychological disturbance is often referred to as hypochondriasis. Barsky and Klerman defined the four main characteristics of hypochondriasis as: a) physical symptoms disproportionate to demonstrable organic disease; $b$ ) a fear of disease and the conviction that one is sick; c) a preoccupation with one's body, and d) the persistent and unsatisfactory pursuit of medical care. ${ }^{8}$ Although this definition finds general acceptance, there is continuing controversy over the status of hypochondriasis as a disease. ${ }^{8-10}$ In the case of specific fears of STD, MacAlpinem ${ }^{11}$ and de Kite and Grimble $^{12}$ have argued that syphilophobia and venereophobia are not unitary conditions but rather non-specific symptoms of a range of psychiatric disorders.

Leaving aside the issue of nosological categories, there is the more immediate problem of defining and using the overall concept of hypochondriasis. When there are clear cut features of morbid bodily concern, such as obsessional ruminations about illness, atypical distribution of symptoms, or frank misperceptions of signs, this is strong suggestive evidence of an underlying psychological aetiology. Usually in these cases the diagnosis of hypochondriasis is made before the psychiatric referral.

In the absence of these clear cut features, the doctor is faced with making an assessment on the basis of the patient's consultation behaviour alone. It is then that the psychiatrist may be asked whether there is sufficient psychological disturbance to account for the somatic complaints. This introduces into the diagnostic process a consideration of aetiological mechanisms, usually a search for evidence of a shift from the psychological to the somatic. ${ }^{13-15}$

The hypothesis of a shift from psyche to soma relies on the identification of underlying psychological disturbance. Once the shift has taken place, however, the psychological disturbance has of necessity become a covert one. The reliable identification of covert disturbance is problematic as, to some extent, everyone has underlying emotional problems if they are looked for. One solution to this dilemma is to search for positive evidence of denial. Certainly in the study published here many patients were hostile to psychological exploration, and this could be interpreted as evidence of denial. On the other hand, the patients would claim it was justifiable resentment at not having their physical complaints investigated further. However important the concept of denial may be in aetiological theories, it is extremely difficult to quantify or assess. There are real dangers that some speculative psychological explanation will serve to invalidate the patient's complaints and interfere with future medical management.

There are no follow up studies of patients with hypochondria attending STD clinics so the natural history of psychological or physical developments is not known. Follow up studies in other settings of patients with a diagnosis of "hysteria" differ considerably in the incidence of emerging organic pathology. ${ }^{16} 17$

Patients with hypochondria attending STD clinics can pose difficult diagnostic problems. A number of the factors that contribute to the clinical recognition of this condition have been identified in the study published here. These include details of the patient's physical presentation and behaviour at the clinic. In some cases there appear to be fairly clear grounds for labelling someone a hypochondriac. When these clear cut cases are eliminated, however, there remains an appreciable number of patients for whom the diagnosis rests on consultation behaviour alone. These patients frequently have a history of STD.

Independent psychiatric assessment has no part to play in weighing up the evidence for or against physical pathology. There are few reliable indicators of abnormal consultation behaviour to guide the doctor in his assessment. The recognition of hypochondriasis entails consideration of the total presentation of the patient in the primary consultation setting.

\section{References}

1. Bhanyi S, Mahony JD. The value of a psychiatric service within the venereal disease clinic. British Journal of Venereal Diseases 1978; 54:266-8. 
2. Pedder JR, Goldberg DP. A survey by questionnaire of psychiatric disturbance in patients attending a venereal diseases clinic. British Journal of Venereal Diseases 1970;46: 58-61.

3. Catalan J, Bradley M, Gallwey J, Hawton K. Sexual dysfunction and psychiatric morbidity in patients attending a clinic for sexually transmitted diseases. Br J Psychiatry 1981; 138:292-6.

4. Mayou R. Psychological morbidity in a clinic for sexually transmitted disease. British Journal of Venereal Diseases 1975; 51:57-60.

5. Harrison RM. Illness behaviour and sexually transmitted diseases. British Journal of Venereal Diseases 1979; 55: 125-6.

6. Pilowsky I, Spence ND. Patterns of illness behaviour in patients with intractable pain. J Psychosom Res 1975; 19: $279-87$.

7. Pedder JR. Psychiatric referral of patients in a venereal diseases clinic. British Journal of Venereal Diseases 1970;46: 54-7.

8. Barsky AJ, Klerman GL. Overview: hypochondriasis, bodily complaints and somatic styles. Am J Psychiatry 1983;140:273.
9. Kenyon FE. Hypochondrical states. Br J Psychiatry 1976; 129: $1-14$.

10. Mayou $\mathrm{R}$. The nature of bodily symptoms. Br J Psychiatry 1976; 129:55-66.

11. Macalpinem I. Syphilophobia. British Journal of Venereal Diseases 1957;33:92-9.

12. Kite EC de, Grimble A. Psychiatric aspects of venereal disease. British Journal of Venereal Diseases 1963;39:173-80.

13. Lesse S. The multivariant masks of depression. Am J Psychiatry 1968; 124 suppl: 35-40.

14. Pilowsky I, Bassett DL. Pain and depression. Br J Psychiatry 1982;141:30.

15. Sifneos PE. The prevalence of 'alexithymic' characteristics in psychosomatic patients. Psychother Psychosom 1973;22: 255-62.

16. Slater E. Diagnosis of "hysteria". Br Med J 1965; i: 1395-9.

17. Guze S, Perley M. Observations on the natural history of hysteria. Am J Psychiatry 1963;119:960-5. 